\title{
Pars plana vitrectomy with the "reinverting operating lens system": a step-up in vitreo retinal surgery
}

Vitrectomia via pars plana com "sistema de lentes de inversão operatória ": um passo a frente em cirurgia vitreo-retiniana

Osias Francisco de Souza

Newton Kara-José

\section{A B S T RA C T}

Objective: To analyze the efficacy of the panoramic viewing system(PVS) Reinverting Operating Lens System(ROLS) and the plano-concave Landers lens system in pars plana vitectomy (PPV). Methods: The authors retrospectively analyzed the records of $117 \mathrm{PPV}, 87$ patients, performed between December 1996 and August 1998. The PPV was divided into two groups. Group 1 included 54 surgeries, with the Landers system. Group 2 included 63 surgeries with the ROLS. Results: There were no statistical significant differences between the two groups, regarding pre and postoperative parameters. Surgeries employing the Landers system had an average time significantly higher than the ROLS group $(\mathrm{p}<0.001)$. When the surgical time was analyzed according to the disease, surgeries lasted significantly longer when the Landers system was used $(\mathrm{p}<0.05)$, except for the Uveitis group $(\mathrm{p}=0.262)$. Surgeries in group 2 required less air-fluid and lens exchanges, less use of perfluorocarbon liquid (PFCL), and less need for scleral depression during the procedure. Conclusion: The use of ROLS significantly reduced the time for PPV, lowering the need for air-fluid exchange, lens exchange, PFCL use, and scleral depression. The PVS ROLS offered several advantages over the Landers plano-concave lens system during the surgery, without changing the final results.

Keywords:Vitrectomy/methods;Ophthalmologic surgical procedures/methods;Retinal diseases/surgery

INTRODUCTION

Since three-port pars plana vitrectomy (PPV) was first performed in a human in $1970^{(1)}$, vitrectomy techniques have improved continuously in order to be more efficient. In the view system, the clearest, most magnified, and widest view are the goal.

Until recently, one of the most widespread viewing systems for pars plana vitrectomy was the Landers System, which includes a posterior pole lens and prismatic lenses for peripheral imaging. These lenses provide a beautiful visual angle of $30^{\circ}$, however, need maneuvers of scleral depression for peripheral image, especially in cases of media opacity and/or gas tamponades ${ }^{(2-5)}$. In 1987, the panoramic viewing system (PVS) called BIOM (binocular indirect ophthalmomicroscope) was introduced, which provides ora serrata anatomical field of view and significantly improves vision through cloudy media and small pupils ${ }^{(6)}$. Subsequently, several authors confirmed the efficiency of the PVS ${ }^{(7-13)}$. However, this system is not used by many surgeons. The BIOM has disadvantages when compared to the Landers system ${ }^{(8)}$. 
One important PVS developed was ROLS (Reinverting operating lens system). ROLS showed the same advantages as the Landers system besides providing panoramic image.

The purpose of this retrospective study is to compare the efficiency of PPV performed with the PVS ROLS and the Landers system, in a serie of 117 consecutive surgeries.

\section{ME T H O D S}

The authors reviewed the records of 117 consecutive PPV (87 patients) using either the PVS ROLS or Landers system, at a private clinic in Campinas, Brazil. One vitreoretinal surgeon (OFS) performed all surgeries, with the same equipment, with the exception of the viewing system.

Eyes were divided into two groups (groups 1 and 2), according to the viewing system used. Group 1 included 54 PPV, with the Landers plano-concave and prismatic lenses (Optikon, Rome, Italy), between December 1996 and December 1997, and Group 2 included 63 PPV with the ROLS: Stereo diagonal image inverting, super macula VIT, central retina VIT and mini quad XL VIT contact lenses (VOLK® Mentor, Ohio USA), between January 1998 and August 1998.

The following preoperative variables were obtained from the records: demographic (patient age, gender and race), visual acuity, and preoperative diagnosis. Proliferative vitreoretinopathy (PVR) was classified according to the 1991-PVR classification $^{(14)}$.

Six intraoperative parameters were analyzed: duration of surgery (obtained from the anesthesia chart), number of changes of lenses, number of air-fluid exchanges, the necessity of scleral depression during the surgery, difficulty of laser application, and the use of perfluorocarbon liquid (PFCL).

Postoperatively, the incidence of anatomic success, the final visual acuity, and the necessity of reinterventions were analyzed.

We defined difficulty of laser application as: a) the necessity of interruptions due to loosening of surgical view; b) $50 \%$ increase in the initial energy. (The initial energy was the minimal to obtain a threshold lesion in the retina, without the risk of creating a hemorrhage. The mean initial energy was $300 \mathrm{mw}$, ranging from 250 to $350 \mathrm{mw}, 0.5$-second duration). In all cases, the HGM compact plus laser (HGM Medical Laser Incorporated Salt Lake City Utah, USA), was used.
Postoperatively, we defined anatomic success as a complete attachment of the sensorial retina to the RPE (retinal pigment epithelium), and anatomic failure as partial retinal attachment, globe atrophy or severe hypotony (intraocular pressure $<4 \mathrm{mmHg}$ ).

Eyes requiring repeated vitreous surgery were included in the analysis, with follow-up data obtained for all patient 5 months or more after their most recent surgery. Univariate analysis was performed using either the Chi-square analysis, Fisher's exact test, or Student's $t$ test. We defined statistical significance as $\mathrm{p}<0.05$.

\section{RE S U L T S}

\section{Preoperative parameters}

There were no significant differences between the groups regarding age, gender, race, and preoperative visual acuity $(\mathrm{p}>0.05)$ (Table 1). Furthermore, the preoperative diagnoses were not found to be statistically different between the groups ( $>0.05$ ) (Table 2). Also, the number of eyes previously operated, was not statistically different between the groups, 10 in group 1 and 13 in group $2(\mathrm{p}=0.791)$. In both groups, a similar number of patients with diabetic retinopathy had been previously treated with argon laser: $12 / 13$ in group 1 and 13/14 in group $2(\mathrm{p}=1.00)$ (Table 1$)$.

\section{Intraoperative parameters}

Surgeries employing the Landers system had an average time of $123.0 \pm 35.6$ minutes, significantly higher than the ROLS $(87.0 \pm 31.5$ minutes $)(p<0.001)$ (Table 3$)$. When the surgical time was analyzed according to the diagnosis, surgeries lasted significantly longer when the Landers system was used $(\mathrm{p}<0.05)$, except for the uveitis group $(\mathrm{p}=0.262)$ (Table 3$)$.

In group 1, two or more lens exchanges were needed in 52 cases $(96 \%)$, mainly to enhance the peripheral view with prismatic lenses. In group 2, two or more lens exchanges were needed in 19 cases $(30 \%)$, in order to increase the quality of the image of the posterior pole, and to perform membrane peeling $(\mathrm{p}<0.001)$.

Air-fluid exchange and subretinal fluid drainage were performed 2 or more times in 30 surgeries $(55 \%)$ of group 1, and in one surgery $(1,5 \%)$ of group $2(\mathrm{p}<0.001)$.

\begin{tabular}{|c|c|c|c|}
\hline \multicolumn{4}{|c|}{ Table 1. Demographic data forall study subjects } \\
\hline & Group $1(n=54)$ & Group $2(n=63)$ & $\mathbf{p}$ \\
\hline \multicolumn{4}{|l|}{ Age (years) } \\
\hline Mean & 54.4(14.6) & $56.9(14.9)$ & 0.583 \\
\hline Range & $16-77$ & $20-81$ & \\
\hline Race & $W=50 ; B=3 ; A=1$ & $W=60 ; B=1 ; A=2$ & 0.448 \\
\hline \multirow[t]{2}{*}{ Preoperativevisualacuity } & $L P-H M=41$ & $L P-H M=43$ & \\
\hline & $C F-20 / 200=13$ & $C F-20 / 200=20$ & 0.413 \\
\hline Previous argonlaserfordiabetic & $12 / 13$ & $13 / 14$ & 1.00 \\
\hline
\end{tabular}




\begin{tabular}{|c|c|c|c|}
\hline Diagnosis & $\begin{array}{c}\text { Group } 1 \\
(n=54)\end{array}$ & $\begin{array}{c}\text { Group } 2 \\
(n=63)\end{array}$ & $\mathbf{p}$ \\
\hline RetinaldetachmentwithPVR uptogradeA & 9 & 10 & 1.00 \\
\hline Retinal detachment with PVR grades $B$ and C (Por A) & 21 & 25 & 1.00 \\
\hline Diabetic VH,epiretinalmembranes, andmaculartractionRD & 10 & 13 & 0.791 \\
\hline Diabetic VHwithoutRD & 3 & 1 & 1.00 \\
\hline Nondiabetic vitreous hemonhage & 5 & 6 & 1.00 \\
\hline Vitreousopacitysecondarytouveitis & 3 & 4 & 1.00 \\
\hline Intravitreous IOLorlens & 3 & 4 & 1.00 \\
\hline
\end{tabular}

\begin{tabular}{|c|c|c|c|}
\hline Diagnoses & $\begin{array}{c}\text { Group } 1 \\
(n=54)\end{array}$ & $\begin{array}{c}\text { Group 2 } \\
(n=63)\end{array}$ & $\mathbf{p}$ \\
\hline RetinaldetachmentwithPVR uptogradeA & $142.7 \pm 16.4$ & $85.5 \pm 22.1$ & $<0.001$ \\
\hline Retinal detachment with PVR grade $B$ and C (PorA) & $153.8 \pm 14.8$ & $113.6 \pm 24.7$ & $<0.001$ \\
\hline Diabetic HV,epiretinalmembranes, maculartractionRD & $80.7 \pm 14.8$ & $55.0 \pm 8.3$ & $<0.001$ \\
\hline Diabetic HVwithoutRD & $70.0 \pm 10.0$ & $50.2 \pm 8.1$ & $<0.001$ \\
\hline Nondiabetic vitreous hemonhage & $92.0 \pm 5.7$ & $68.3 \pm 13.3$ & 0.006 \\
\hline Vitreous opacitysecondarytouveitis & $93.3 \pm 5.7$ & $79.0 \pm 33.2$ & 0.262 \\
\hline Intravitreous IOLorlens & $113.3 \pm 20.8$ & $93.7 \pm 17.9$ & 0.015 \\
\hline Total-Averagetime & $123.0 \pm 35.6$ & $87.0 \pm 31.4$ & $<0.001$ \\
\hline \multicolumn{4}{|l|}{ PVR:proliferativevitreoretinopathy;|OL:intraocularlens } \\
\hline
\end{tabular}

During the surgical procedure, scleral depression to allow peripheral visualization was necessary in 52 cases $(96 \%)$ in group 1 , and once $(1.5 \%)$ in group 2 due to marked posterior capsule opacity $(\mathrm{p}<0.001)$ (Table 4$)$. After the surgical procedure, scleral depression was performed in all cases to ensure that there was no peripheral retina hole.

Endophotocoagulation was considered easier in group 2, with no interruptions and no necessity of increased energy. In group 1, interruptions were significantly more frequent $(61 \%)$, as well as the necessity of increased energy $(p<0.001)$ (Table 4).

The use of PFCL was necessary in 15 cases $(27.7 \%)$ in group 1 , and 9 cases $(14.28 \%)$ in group $2(p=0.050)$.

\section{Postoperative parameters}

Mean follow-up was $7.96 \pm 2.55$ months in Group 1 and 8.65 \pm 3.17 months in Group $2(\mathrm{p}=0.33)$. There was no statistically significant difference between the groups in terms of anatomic success, reinterventions, anatomic failures, and postoperative visual acuity (Table 5).

\begin{tabular}{|lccc|}
\hline \multicolumn{4}{|c|}{ Table4.Surgery parameters accordingtodiagnosis } \\
Group & $\mathbf{G 1}$ & $\mathbf{G 2}$ & $\mathbf{P}$ \\
& $(\mathbf{n = 5 4 )}$ & $(\mathbf{n = 6 3 )}$ & \\
Air-fluidexchange & 30 & 1 & $\varangle 0.001$ \\
Difficultyoflaserapplication & 30 & 1 & $\varangle .001$ \\
Vitrectomylensexchange & 52 & 19 & $\varangle .001$ \\
Perfluorocarbonliquid & 10 & 4 & 0.050 \\
Scleraldepression & 52 & 1 & $\varangle .001$ \\
\hline
\end{tabular}

\section{O M M E T}

Pars plana vitrectomy (PPV) was first performed by Machemer et al. in 1970 and has profoundly changed ophthalmic surgery, helping several patients who were previously considered untreatable ${ }^{(1)}$. Since the introduction of PPV, intraoperative imaging of the surgical field has been a challenging issue, and the object of continuous research aimed at providing the surgeon with the clearest, most magnified, and widest field of $\operatorname{view}^{(7-8,15)}$.

The first PVS was called BIOM with a $\mathrm{SDI}^{(6,16)}$. BIOM consisted of a telescopic system connected to the microscope, with a 90 or 60 diopter (D) lens positioned 10 to $20 \mathrm{~mm}$ above the cornea, providing an excellent wide-angle view of the fundus ${ }^{(8)}$. However, the use of this system was not described by several surgeons ${ }^{(8)}$. BIOM has disadvantages when compared to the Landers system: First, focusing has to be done manually. Second, translations of the microscope have to be very precise. Third, there is some risk that the lens, positioned 10 to $20 \mathrm{~mm}$ above the cornea, will touch the cornea if there is any inadverted downward movement of the microscope $^{(8)}$. The Landers system remained to be the most used ${ }^{(11-12)}$. Subsequently, several authors confirmed the efficiency of $\mathrm{BIOM}^{(11-12)}$, whereas others described different systems to obtain wide-angle viewing, such as the one produced by Advanced Vitreoretinal Instruments (AVI Ltd. New York NY), with noncontact lenses ${ }^{(7,10,13)}$.

PVS ROLS developed by VOLK ${ }^{\circledR}$, showed similar advanta- 


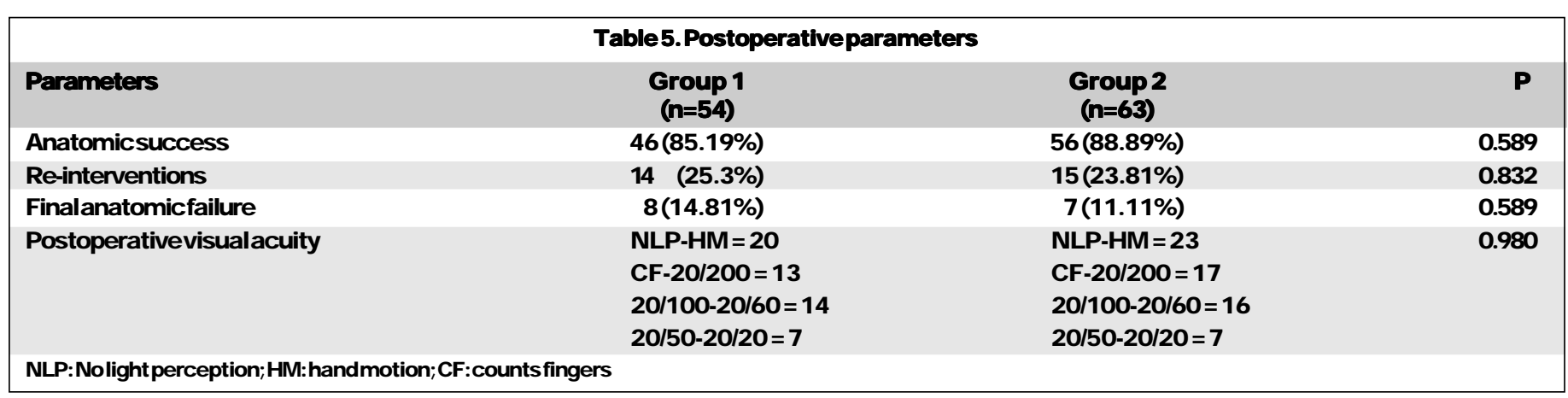

ges as those of Landers System, besides panoramic viewing. However, it is surprising that comparisons between different viewing systems are not frequent in the literature. In a revision of 192 records of eyes undergoing retinotomy procedures with either the Landers system or the PVS AVI, the findings indicated that the surgery duration, the need for scleral depression, and the number of laser spots were significantly lower when the PVS was employed ${ }^{(7)}$.

The present study reports data from 117 consecutive PPV using two different viewing systems: the ROLS and the Landers system. However, we analyze 5 different procedures during PPV (Table 4).

There was no statistically significant difference between the two groups in terms of demographic data, preoperative visual acuity, or preoperative diagnosis, and in both groups, a similar number of patients with diabetic retinopathy had been previously treated with argon laser (12/13 in group 1 and 13/14 in group $2(\mathrm{p}=1.00)$, which suggests that the two groups were homogeneous in terms of preoperative vitreoretinal conditions (Table 1 and 2).

Surgeries lasted significantly longer when the plano-concave Landers System was employed (Table 3), which can be explained for several reasons. It may be secondary to an improvement in the peripheral view obtained with ROLS, reducing the number of interruptions, to exchange lenses (Table 4). With ROLS (Group 2), a significantly lower lens exchange rate was observed when compared to Group 1, therefore lowering the duration of the procedure, and possibly reducing the risk of intraoperative corneal edema ${ }^{(17-18)}$. However, the occurrence of corneal edema was not evaluated in the present study.

Air-fluid exchange frequently causes a glare back toward the surgeon's eyes from the retina and the endo-drainage instruments ${ }^{(7,16)}$. Table 4 shows that air-fluid exchanges with subretinal fluid drainage were more frequently performed in group 1, and consequently consumed more surgical time. In group 2, air-fluid exchanges were easier, which indicates better visualization through the air when ROLS is used.

The low need for scleral depression during the surgery observed in the ROLS group was an important improvement in surgeries requiring peripheral procedures such as retinotomies and retinectomies. However, the above results do not include the need for scleral depression after surgery, in order to inspect the retina periphery. In the Landers group, scleral depression was necessary in 52 surgeries, increasing the duration of the procedure, and peripheral maneuvers. PVS provides clear and adequate visualization of the ora serrata with no need for scleral depression or excessive widening of the pupil, in the majority of the cases ${ }^{(6,15)}$.

Endophotocoagulation in the air-filled eye was greatly facilitated in group 2, where laser application had no interruptions due to loosening of the surgical view, or increase in the initial energy ( $300 \mathrm{mw}$, ranging from 250 to $350 \mathrm{mw}, 0.5$-second duration). In group 1, however, 30 interruptions in endophotocoagulation were necessary, as well as an increase in burn intensity to obtain the same level of photocoagulation.

PFCL is frequently used as a second intraocular hand, mainly in cases of membrane peeling, PVR dissection and retinal attachment before endophotocoagulation ${ }^{(19)}$. Although the use of PFCL has improved the prognosis of more complex cases, it adds more time to the surgical procedure, and may induce retinal toxicity ${ }^{(20)}$. In group 1, PFCL was necessary in 15 cases, whereas in group 2, it was used in only 9 surgeries $(\mathrm{p}=0.050)$. In this group, there was no need for the use of PFCL in cases of retinal attachment with PVR up to grade B, because both the posterior pole and peripheral regions were viewed simultaneously, allowing adequate visualization of the drainage process through the subretinal space, using the original retinal hole. Also, PFCL was not necessary during PVR dissection in 16 of 25 cases with PVR grade C.

Table 5 shows no significant difference between the two groups in terms of postoperative parameters, including anatomic success, number of reinterventions, anatomic failure, and postoperative visual acuity, suggesting that the two groups were homogeneous in terms of final results. Moreover, the surgical results were similar to previously published series ${ }^{(21-23)}$.

Although this was not a prospective, randomized study, it is important to emphasize that there was no learning curve between the two groups, since all surgeries were performed by the same surgeon, who had been using the Landers system to perform surgeries for a long period of time (4 years). The learning curves for ROLS in the present study was relatively short (approximately 12 surgeries, not included in the study). A previous report suggests about 10 surgeries using PVS AVI as a learning curve ${ }^{(7)}$. 
We conclude that ROLS offered several advantages over the Landers system during the surgical procedure. ROLS presents the same characteristics as the Landers system as well as providing panoramic view of the retina. In recent years, the use of both systems in the same PPV, has become routine. We believe that this new generation of viewing system has been an important advance in the surgical management of vitreoretinal diseases, comparable to the introduction of vitreoretinal forceps, PFCL or the use of long-duration intraocular gases.

\section{RE S U M O}

Objetivos: Analisar a utilização dos sistemas de Landers e o sistema panorâmico de lentes de inversão operatória (ROLS) em vitrectomia via pars plana (PPV). Métodos: Estudo comparativo entre PPV realizadas com os sistemas ROLS e sistema Landers. Foram analisados retrospectivamente os dados de 117 PPV realizadas em 87 pacientes, no período entre dezembro de 1996 e agosto de 1998, divididos em 2 grupos, de acordo com o sistema de vizibilização utilizado. O grupo 1 foi formado com 54 cirurgias e utilizou o sistema plano-convexo de Landers. O grupo 2 foi formado com 63 cirurgias e utilizou o sistema ROLS. Resultados: Não houve diferenças estatisticamente significativas entre os dois grupos nos parâmetros pré e pósoperatórios. As cirurgias que utilizaram o sistema Landers tiveram um tempo médio de duração significativamente maior que o das cirurgias que utilizaram o sistema ROLS $(p<0,001)$. A análise dos tempos cirúrgicos de cada uma das doenças, também mostrou que as cirurgias foram significativamente mais demoradas com a utilização do sistema Landers $(p<0,05)$, com exceção para o grupo de Uveítes $(\mathrm{p}=0,262)$. As cirurgias do grupo 2 necessitaram de menor número de trocas fluídogasosas (TFG), menor uso de perfluorocarbono líquido (PFCL) e menor necessidade de realizar depressão escleral durante as cirurgias. Conclusões: O uso do sistema panorâmico ROLS reduz de modo significativo o tempo da PPV, a realização de trocas fluído-gasosas, o uso de PFCL, as trocas de lentes e os procedimentos de depressão escleral. O sistema panorâmico ROLS ofereceu vantagens sobre o sistema Landers, durante as PPV, sem alterar os resultados cirúrgicos finais.

Descritores: Vitrectomia/métodos; Procedimentos cirúrgicos oftalmológicos/métodos; Doenças retinianas/cirurgia

\section{REF ERENCES}

1. Machemer R. Reminiscences after 25 years of pars plana vitrectomy. Am J Ophthalmol 1995;119:505-10.

2. Parel JM, Machemer R. Steam-sterilizable fundus contact lenses. Arch Ophthalmol 1981;99:151.

3. Landers MB, Stefansson E, Wolbarsht ML. The optics of vitreous surgery. Am J Ophthalmol 1981;91:611-4.

4. Berrod JP, Rozot P, Raspiller A, Thiery D. Fluid air exchange in vitreo retinal surgery. Int. Ophthalmol 1994-95;18:237-41.

5. Tolentino FI, Freeman HM. A new lens for closed pars plana vitrectomy. Arch Ophthalmol 1979;97:2197-8.

6. Spitznas M. A binocular indirect ophthalmomicroscope (BIOM) for noncontact wide-angle vitreous surgery. Graefes Arch Clin Exp Ophthalmol 1987;225:13-5.

7. Lesnoni G, Billi B, Rossi T, Stirpe M. The use of panoramic viewing system in relaxing retinotomy and retinectomy. Retina 1997;17:186-90.

8. Bovey EH, Gonvers M. A new device for noncontact wide-angle viewing of the fundus during vitrectomy. Arch Ophthalmol 1995;113:1572-3.

9. Peyman GA. A new wide-angle irrigating contact lens for pars plana vitrectomy. Can J Ophthalmol 1988;23:150.

10. Corcóstegui B. New developments in wide-angle fundus viewing planitis. Vitreoretinal Surg Technol 1994;6:3-4.

11. Senn P. Pratical experiences in conversion to the wide angle observation systems for vitreous surgery BIOM, SDI, VPF. Klin Monatsbl Augenheilkd 1991;198:480-1.

12. Oldendoerp J. Fluid-gas exchange in vitreous surgery using the BIOM, VPFS, SDI wide-angle observation systems. Klin Monatsbl Augenheilkd 1989;194:129-32.

13. Eckardt C, Wiechens B. A convexe-concave contact lens for vitreoretinal operations with the BIOM. Klin Monatsbl Augenheilkd 1991;198:64-5.

14. Machemer R, Aaberg TM, Freeman HM, Irvine AR, Lean JS, Michels RM. An update classification of retinal detachment with proliferative vitreoretinopathy. Am J Ophthalmol 1991;112:159-65.

15. Ohji M, Tano Y. Double-mirror peripheral vitrectomy lens. Arch Ophthalmol 1995;113:1460-1.

16. Spitznas M. Reiner J. A stereoscopic diagonal inverter (SDI) for wide-angle vitreous surgery. Graefes Arch Clin Exp Ophthalmol 1987;225:9-12.

17. Verstraeten T, Williams GA, Chang S, Cox MS, Trese MT, Moussa M, Friberg TR. Lens-sparing vitrectomy with perfluorocarbon liquid for the primary treatment of giant retinal tears. Ophthalmology 1995;102:17-20.

18. Han DP, Lewis MT, Kuhn EM, Abrams GW, Mieler WF, Williams Ga, Aaberg TM. Relaxing retinotomies and retinectomies. Surgical results and predictors of visual outcome. Arch Ophthalmol 1990;108:694-7.

19. Chang S. Low viscosity liquid fluorochemicals in vitreous surgery. Am J Ophthalmol 1987;103:38-43.

20. Chang S, Sparrow JR, Iwamoto T, Gershbein A, Ross R, Ortiz R. Experimental studies of tolerance to intravitreal perfluoro-n-octane liquid. Retina 1991;11:367-74

21. Chang S, Coleman DJ, Lincoff H, Wileox LM, Braunstein RA, Maisel JM. Perfluoropropane gas in the management of proliferative vitreoretinopathy. Am J Ophthalmol 1984;98:180-8.

22. Cox MS, Trese MT, Murphy PL. Silicone oil for advanced proliferative vitreoretinopathy. Ophthalmology 1986;93:646-50.

23. Hanneken A, Michels RG. Vitrectomy and scleral buckling methods for proliferative vitreoretinopathy. Ophthalmology 1988;95:865-9.

\section{Ao enviar um artigo para publicação, leia ATEN TAMENTE as instruções para autores, constante no final de cada fascículo.}

